\title{
THE BEGINNINGS OF THE ROYAL ALBERT HOSPITAL
}

Joe Alston, Administrator 1938-78

The early part of the nineteenth century was a period of reform, not least of which was the segregation of idiots and imbeciles from lunatics in asylums.

The Commissioners in Lunacy and the medical profession condemned such an association as being in all respects objectionable. Idiocy was generally considered to be accompanied by an abnormal or imperfectly developed organism, which retarded the growth of the intellectual and moral powers. The Mental Deficiency Act of 1913 defined idiots as being persons so deeply defective in mind from birth or from an early age as to be unable to guard themselves against common physical dangers. Idiots therefore were thought to require a distinct treatment in separate institutions, where the resources of the skilled physician could be best employed for the modification or correction of those defects which obscure the mind. Imbeciles, according to the above act, were persons in whose case there existed from birth or from an early age mental defectiveness not amounting to idiocy, yet so pronounced that they were incapable of managing themselves or their affairs, or in the case of children, being taught to do so.

Prior to this time, the idiot or imbecile child was invariably accommodated, not only in the same building but also in the same wards as the victims of:

- dementia deterioration of mental faculties, combined with emotional disturbances

- melancholia a mental disorder characterised by feelings of dejection and, usually, by withdrawal

- chronic mania a state of mind characterised by profuse and rapidly changing ideas that may quickly change to irritability or violence.

Prior to the establishment of the Royal Albert, local arrangements for such people were variable, to say the least. Some were accommodated in workhouses, some in lunatic asylums such as the county asylum at Lancaster Moor. Some were kept at home and some confined to the house or even an outhouse in order to escape the stigma of having such a child, regarded by some as possessing a devil. Others would be moved out of the area and taken to a place where they were unknown.

Much concern for these most unfortunate creatures was shown by Dr Edward Denis de Vitre of Lancaster, but for many years he was not able to help those he identified as being in need of special care. Dr de Vitre had been interested in this area of medicine for some time, and the following are extracts from a paper read by him "on the necessity of an extended legislative protection to persons of unsound mind" at a meeting of the Association of Medical Officers of Hospitals held in London in June 1843. The cases referred to were furnished by a superintendent of a County Lunatic Asylum.

\section{“I. A pauper-lunatic about 28 years of age.}

From infancy he had been of weak intellect; and as his parents could not afford to stay at home to take care of him, and could not pay anyone to do so for them, he was, for the sake of security, shut up in a cupboard beneath the staircase of a country cottage, where were kept the small supply of coals and firewood, besides mops, bucket etc. The lad grew, but his locality did not grow with his increased dimensions:he had eyes also, but there was no light for him to employ them by:- he was hungry, but had nothing in the long day's absence of his parents, wherewith to satisfy his appetite. Years rolled on, and this state of things continued when the New Poor Law required that, as a person chargeable to the parish, he should be removed to the workhouse. He was in such a loathsome state of filth that they could not secure him beyond an outhouse, and he was forwarded to the Asylum as soon as possible. When brought to us he appeared, from the contracted and compressed form of his body, not above thirty inches high, but when gradually drawn up to the erect posture he was five feet nine inches. From the nature of his confinement, his body had become bent upon his thighs, and these so strangely bent upon his legs, that the knees were brought up under the armpits, and upon his knees he rested as upon crutches. Occasionally he changed this position for one on which he rested on the sacrum, the skin of which was indurated like that of the Simia tribe, bringing his knees more forward, and resting his chin upon them. He was blind, not from ulceration or opacity of the cornea, but from sheer disuse: the organ appeared to have dwindled away, and the eyelids to have closed. Occasionally he would sit facing the sun, apparently in enjoyment, when a small cornea was perceptible; and at these times only would he permit us to see his eyes, or would open his eyelids. He was deaf; or at least inattentive to all sounds: he had no idea of walking, making progression with his knees placed under his armpits and resting and helping himself forwards by the palms of his hands. His body and face were free from hair, and he had only a thin coarse kind on his head, and scarcely any eyebrows. His appetite was depraved - he would eat dirt, grass, or any thing that came in his way; and he invariably, if not prevented, ate his own faeces. He died after a few years residence with us, but without having shown any signs of improvement.

II. Another case was that of a woman nearly sixty years of age of naturally quick and intelligent mind. She had been confined by restraint for nearly thirty years, by being fastened to the bedstead in a common thoroughfare on the ground floor of a house in a country town. The only means she had of changing her position and relieving her constrained posture was by turning on either side. Stretch herself she could not, as her bed, a species of trough, did not admit of her doing so. When brought to the Asylum she had lost entirely the use of her limbs and, when placed on her feet, had no more power of balancing than a newly born child. Her knees and hip joints were rigidly fixed, as were her shoulders and elbows, her arms having been constantly fastened to her sides. This particular case came to the Asylum, and was reported to be so violent (with contracted limbs!) as to be unfit for the poor-house. She was noisy and 
boisterous, and we wonder after the cruelties she had endured: but she could not be violent, and it required neither a stretch of responsibility, nor a great share of humanity to remove all fetters from her contracted body. By a proper course of treatment this poor creature rapidly recovered: but not belonging to the county of the Asylum which took her in, she was removed by the overseers, on account of the expense, so soon as they were satisfied that she was not dangerous.

Dr de Vitre, at the time a local GP and visiting physician to the County Asylum, was called to a private consultation by a Mr James Brunton, a local book-keeper and a member of the Society of Friends, who, during their conversation, expressed a desire to see established in Lancaster an asylum for the idiots and imbeciles in the surrounding area, for which he would donate without condition $£ 2,000$. De Vitre saw wide possibilities in the idea and on 14th November 1864 he called a meeting of ten Lancaster gentlemen, including James Brunton, whose offer of $£ 2,000$ was considered and accepted.

The others present were Mr James Grant, Dr JS Harrison, Dr T Howitt, Mr JL Milner, Mr EG Paley, Mr S Ross, Mr A Seward and Mr J Sharp. A provisional committee was formed consisting of the ten men with the addition of $\mathrm{Mr}$ William Roper and Mr Thomas Storey. Dr de Vitre acted as chairman and $\mathrm{Mr}$ Grant as honorary secretary. The name selected for the proposed institution was The Northern Counties Asylum for Idiots, afterwards expanded to The Northern Counties Asylum for Idiots and Imbeciles. The asylum would cater for the needs of the six northern counties - Lancashire, Yorkshire, Westmorland, Cumberland, Durham and Northumberland. In March 1866 Cheshire's application for inclusion as the seventh northern county was accepted.

An institutory meeting was held in the Shire Hall of Lancaster Castle on 21st December 1864, where the proposals were put forward and agreed. Much publicity was given to the project locally, regionally and nationally, with the press promoting the need for such an institution. The first recorded donation on 5th December 1864 was $£ 440$ from the Ripley Celebration Fund. Committees were formed in the leading towns of the seven counties and Ladies Committees were supplied with collecting purses. Many very successful fundraising events were organised, and meetings were held in the larger towns, including the AGM, or GAM, as they were called in those early days.

\section{THE FIRST ANNUAL REPORT, 1865}

"A year has now elapsed since this project was instituted at a public meeting held in the Shire Hall, Lancaster. The Committee then appointed deem it courteous to that meeting and to the subscribers generally, to issue a brief report of their labours to the close of the present year.

The Committee have been actively engaged during the year in correspondence with the Members of Parliament, Magistrates, Clergy, and other influential persons in every part of the district; and in sending out a pamphlet of their proceedings, and publications on the treatment of the Idiots by the Rev Edwin Sidney, MrW Millard and others. They rejoice to record that their efforts have been met everywhere by the warmest sympathy and support, and that by these means their funds have been largely augmented. The list of presidents, vice-presidents, subscribers and influential local Committees who are actively engaged in promoting the object fully justifies the firm belief of the Committee at the inauguration of their project, that, with the blessing of God, the cause of the idiot, when fairly brought before a benevolent public would not fail to secure efficient aid: and warrants the Committee's highest anticipations as to the ultimate success of the undertaking. The pecuniary support already promised amounts to $£ 25,073$.

Early in the year communication was held with the Worshipful the Mayor of Liverpool and a few warm friends of the cause there, which resulted in an invitation to attend a public meeting in the Council Chamber. The Mayor presided and, with the assistance of a most efficient Committee, conducted the business to a successful issue. Since then other important public meetings have been held - at York, under the able presidency of His Grace the Archbishop of York; and at Leeds, Bradford and Halifax under the kind patronage and presidency of the respective Mayors. An evening meeting was also held at Halifax, with Sir Francis Crossley, Bart, MP, in the Chair. All these meetings were attended by a deputation from the Central committee, and cordial and unanimous support was given to the project.

Arrangements are already made with influential Local Committees to hold public meetings in the course of a few weeks at Manchester, Hull, Sheffield and Wakefield. It is hoped that all the principal towns in Yorkshire and Lancashire will have been visited by midsummer and that immediate steps will then be taken to bring the project more prominently before the other four Counties.

The Committee would here gratefully recognise their obligations to the various Local Committees and their indefatigable Secretaries, for the energy and support of the benevolent in their districts. They also take this opportunity of thanking those ladies and gentlemen who are so kindly interesting themselves in procuring subscriptions, and in other ways promoting the interests of the Institution. The Committee would also gratefully acknowledge the earnest and cordial advocacy of the public press throughout the district.

In a work of this magnitude and responsibility, the duties devolving upon the Executive demand great energy and perseverance as well as much close personal application, and, indeed, are too onerous to be discharged with efficiency by those who cannot devote their whole time to the purpose. The Committee found it necessary, therefore, to engage a Secretary, and they have been fortunate in securing the services of Mr James Diggens, a gentleman of high character and experience, and who devotes himself zealously to the work.

During the year negotiations have been carried on with the Trustees of Heysham's Charity, for the purchase of about 41 acres of the Greaves Estate, Lancaster; and the Charity Commissioners have recently given their assent to the alienation of the land in question at a cost of $£ 5,613$. The situation is most admirable, having the advantage of dry soil, a suitable elevation, and a south-western aspect, and commanding a charming view of Morecambe Bay with the mountain scenery of Cumberland and Westmorland in the background.

The purchase must be completed in February, and the Committee would, therefore, respectfully request those friends who have not yet paid their subscriptions, to be good enough to do so with as little delay as possible.

Steps will shortly be taken to obtain plans and designs of the building; but these, together with rules and regulations for the management of the Asylum, will require mature consideration.

It is proposed to convene a General Meeting of the subscribers in the ensuing Autumn.

Edward Denis de Vitre

Chairman of the Central Committee" 
The Greaves Estate at that time extended from what is now Sulby Drive (off Greaves Road in Lancaster) to just short of Scotforth village. Scotforth, with its Institution and estate, was not included in the Lancaster municipal area until November 1900 . The boundary at that time was where the island opposite Meadowside Surgery is now situated.

In the summer of $1866 \mathrm{Mr}$ Paley of Lancaster was appointed as architect to the project with instructions to proceed at once to prepare a plan for an asylum to accommodate 400 people, but to make provision in the kitchens, dining room and offices equal to the requirements of double that number.

On 19th December 1866 Queen Victoria granted royal patronage and approved the name Royal Albert Asylum for Idiots and Imbeciles of the Seven Northern Counties, and gave a donation of 100 guineas $(£ 105)$.

The report of the Central Committee, presented to the subscribers at the annual meeting held at York in September 1867, states:

"During the spring the contracts for building the Asylum were publicly advertised. The lowest tenders for the whole building were accepted for the erection of an Asylum to contain 500 inmates exclusive of the general staff; at a cost of 142,000 . This is in excess of the accommodation mentioned in last year's report and is the result of an efficient and economical adaptation of the plan suggested by the Architect. The contract embraces two divisions. The Central position including all the offices (for a much larger establishment than a present contemplated) and the Superintendent's residence forms the first contract and is now in progress. The wings containing the classrooms, dayrooms, bathrooms, lavatories etc form the second contract and are only to be proceeded with on the completion of the Central portion. It is intended to use the central part as a training school for a limited number of pupils whilst the wings are being constructed. An option is reserved to cancel the contract for the immediate erection of the wings on completion of the central portion within six months of signing the contracts, if it be thought advisable to do so. The excavations for the central block are already made, and a great part of the foundations laid; and should the season continue favourable, a large portion of the masonry will be in forward state by next spring when it is proposed to celebrate, under distinguished patronage, the ceremony of laying the foundation stone.

Two hundred and forty Collecting Purses have been issued to ladies in all parts of the district, through which means considerable sums have already been raised, and the Committee have just reason to believe that with such a potent agency they may look forward with confidence to a considerable augmentation of their resources.

Notwithstanding the great success which has crowned every exertion made on behalf of this benevolent project, there yet remains a good deal to accomplish. It is the earnest desire of the Central Committee to hand over to the subscribers a complete establishment for an Asylum for Idiots, FREE FROM ALL DEBT. With so large a portion of the prescribed area still unvisited, and by the Divine Blessing which has hitherto attended their labours, they continually anticipate the successful accomplishment of all they have undertaken.

The contributions from all sources to present date, including a legacy of $£ 500$, amount to $£ 39,876$ l 9s $2 d$.

\section{E D de Vitre}

\section{Chairman"}

The general rules and regulations were adopted on 21 st December 1866. The prospectus states:

"The system of Education includes not only such rudimentary scholastic instruction as is suitable to the feeble intellects of the patients, but embraces also a course of training in the more practical matters of daily life, the cultivation of habits of cleanliness, propriety and selfreliance, and the development of a capacity for useful occupation. In promotion of these objects, patients receive such physical education, and such medical, moral and hygienic treatment as their particular and varied conditions may require.

EPILEPTIC, PARALYTIC AND INSANE PERSONS ARE INELIGIBLE FOR ADMISSION; and those who are incurably HYDROCEPHALIC. Idiocy which is complicated with blindness or deafness, is also a disqualification.

Two classes of patients of both sexes are admitted to the Asylum:-

1 Free patients, whose friends are proved to be unable to meet the lowest payment. They are elected by the votes of the Subscribers, and received for Seven years.

2 Paying patients admitted by the Central Committee, without Election and at any time. "

The foundation stone was laid on 17th June 1868. The day of the foundation stone laying was a major historical occasion for the township of Lancaster. Special trains were laid on from the principal towns of the seven northern counties, bringing in between 8,000 and 9,000 visitors. The Mayor invited the inhabitants to observe a holiday in the town on the Wednesday afternoon, and with a view to facilitate the progress of the procession through the streets he issued a proclamation directing that no persons should, "between the hours of 12 o'clock and 4 o'clock in the afternoon drive any carriage, cart or other vehicle, in, or otherwise obstruct the streets and places appointed as the route of the procession". The entire proceedings were organised in minute detail and full of ceremonial. The foundation stone laying itself was carried out by the Right Hon the Earl of Zetland KT, Most Worshipful Grand Master of the Free and Accepted Masons of England. The mallet used was the one used in laying the foundation stone of St Paul's Cathedral in 1673 by King Charles II. The expenses, including those of the ceremony, platform, banquet, concert, printing and advertising amounted to $£ 95417 \mathrm{~s} 8 \mathrm{~d}$. The ladies' committees' collecting purses yielded $£ 1,605$ and masonic lodge contributions were $£ 264$. The costs were in fact less than the sum allocated, and it was felt that "the advantage of such a ceremony is not to be measured by the actual outlay."

Edward de Vitre's address at the ceremony follows:

"The Royal Albert Asylum for Idiots and Imbeciles of the Seven Northern Counties was projected in the year of our Lord 1864 and had its immediate origin in the munificent offer of $£ 2,000$ by a gentleman to erect a small asylum in the vicinity of Lancaster. A few individuals deeply impressed with the urgent necessity for a large establishment of this kind for the North of England, determined to take advantage of this opportunity offered, and ultimately ventured to appeal to the public for support to erect an asylum to contain from five hundred to eight hundred inmates. Every confidence was entertained that by supplying all available statistical information and showing the great benefits to be conferred by a proper system of education and training of this most helpless class of our fellow creatures, the appeal would not be in vain. It is with unspeakable thankfulness to the Almighty Disposer of all things, that the Central Committee can now record the success which has so far attended their efforts. 
Her Most Gracious Majesty has not only subscribed to the funds, but has permitted the Asylum to be placed under her immediate patronage; the nobility, gentry and indeed all classes of society, have nobly and cheerfully responded to the calls made on their liberality to an extent which justified the Committee in commencing operations by contracting for a building to contain five hundred patients. To complete this building and pay for the necessary land, at least $£ 20,000$ will still be required, but the Committee are animated by the same hope which has hitherto sustained their efforts, and they confidently depend on the continued liberality of the public and the generosity of all who sympathise with suffering humanity.

It is, my Lord, for this Asylum, founded for the most beneficent and humane purposes by the free contributions of a generous and enlightened people that your Lordship as the Most Worshipful Grand Master of Free and Accepted Masons of England has conferred upon the Central Committee the special favour of accepting an invitation to lay the foundation stone.

For the very generous and unhesitating manner in which your Lordship at once acceded to the invitation, evincing the deep interest your Lordship and the Grand Lodge of England take in relieving the sufferings of your fellow creatures, the Central Committee beg, with a deep sense of obligation, to tender their very sincere thanks to your Lordship and all your brethren, who may join in this very important ceremony, and devoutly pray that a Divine blessing may rest upon the sanction your Lordship is about to give this benevolent undertaking."

\section{Edward D de Vitre}

\section{Chairman, Central Committee}

The Grand Master replied:

\section{"Dr de Vitre and Gentlemen}

I thank you sincerely for the address which you have just presented to me, and I assure you that I take the liveliest interest in the institution. When I was asked to give my assent to come down and lay this foundation stone, I assure you I considered it a very great compliment, a higher compliment than I deserved, but I feared that at my age I might be prevented through want of strength to come so far to lay the foundation stone. I am happy to think I am well enough to be able to perform the duty, which I do most gladly. I am not sure whether I am a subscriber, I do not know whether my name is down or not - but it has always been my intention to subscribe. If my name is not already down I will be glad to place 100 guineas at the disposal of the Committee."

In April 1870 building started and in preparation for the imminent completion of the south wing of the main building, the appointment of Dr Shuttleworth, late assistant medical officer at the Earlswood Asylum, was confirmed, as was that of Miss Bryan, former sub-matron at Earlswood, as Matron.

A festival meeting was held on 14th December 1870 as the opening ceremony of the south wing. His Grace the Duke of Devonshire presided, and disappointment was expressed at the failure, despite great effort, to attract a royal personage to the ceremony. Earlswood, where Dr Shuttleworth had worked, was more fortunate when in 1855 their opening ceremony was performed by the Prince Consort.

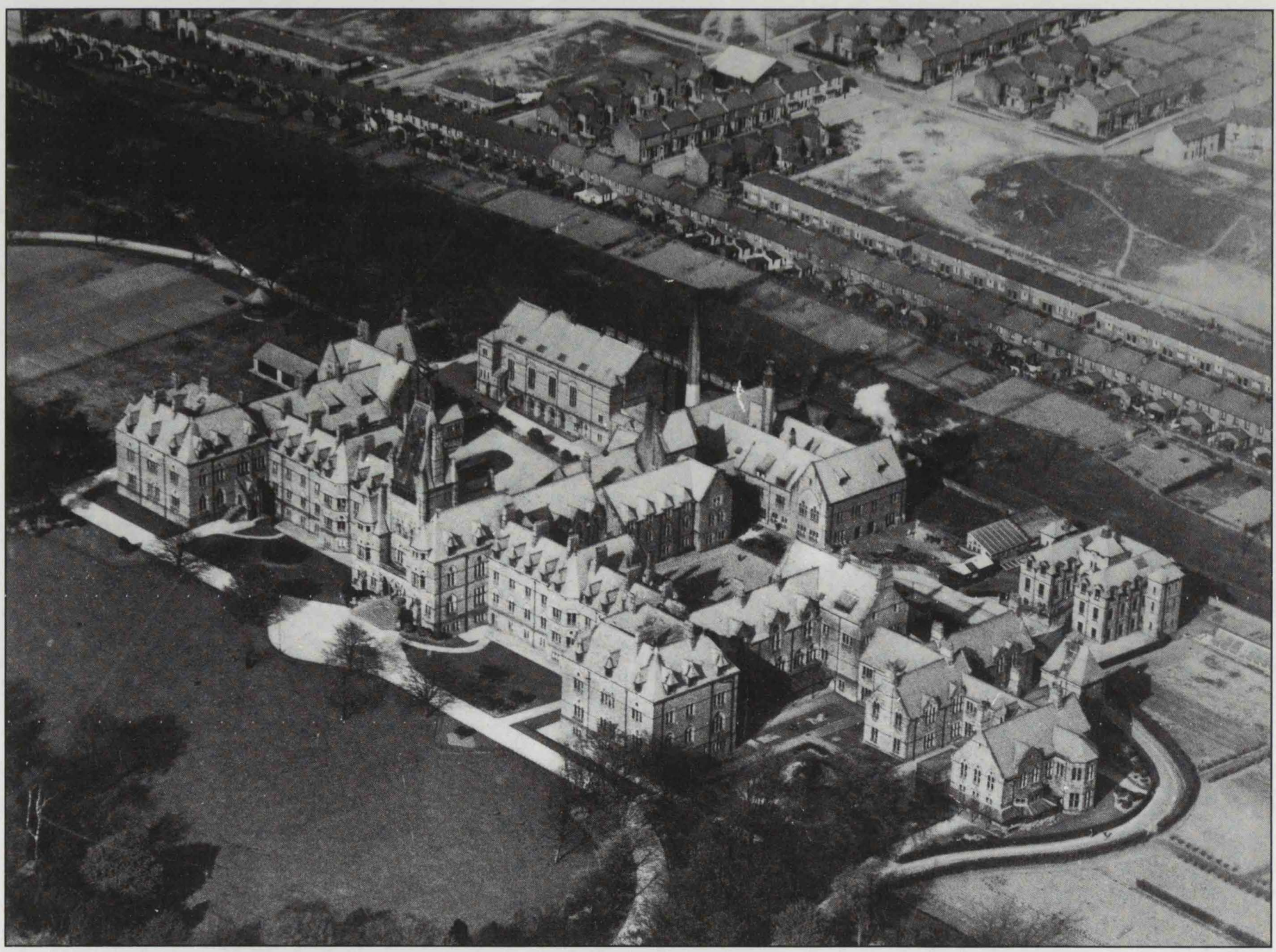

